\title{
Review of the Bank of Russia Conference Inflation: New Insights for Central Banks
}

\author{
Andrey Sinyakov, Bank of Russia \\ sinyakovaa@cbr.ru \\ Ivan Khotulev, Bank of Russia \\ khotulevim@cbr.ru
}

\begin{abstract}
At the beginning of June, the Bank of Russia held in St. Petersburg the international economic research conference Inflation: New Insights for Central Banks. ${ }^{2}$ In its format ${ }^{3}$ and scope of participants, the conference was the first major international event arranged by the Bank of Russia after it switched to the inflation targeting regime in 2015. We are presenting a brief review of the conference, the main results of the studies presented and their potential policy role for central banks. ${ }^{4}$
\end{abstract}

Keywords: inflation, inflation targeting, economic research, Bank of Russia

JEL Codes: E31, E52, F41
Citation: Sinyakov, A. and

Khotulev, I. (2018). Review of the

Bank of Russia Conference Inflation:

New Insights for Central Banks.

Russian Journal of Money and

Finance, 77(3), pp. 3-22.

doi: $10.31477 /$ rjmf.201803.03

\section{Introduction}

The Bank of Russia's choice of inflation as the subject of an international conference could have looked fairly risky at first sight. Most central banks embarked on inflation targeting much earlier than the Bank of Russia did, achieving substantial success in controlling inflation, which is no longer a problem

\footnotetext{
${ }^{1}$ This article reflects the authors' personal views and does not necessarily represent the official position of the Bank of Russia. The Bank of Russia shall not be held responsible for the contents of this article. No reproduction of the materials contained herein is permitted without the authors' consent.

2 The conference program and authors' presentations are available at https://www.cbr.ru/Content/Document/File/43877/programme_june_2018.pdf.

3 The format was as follows: half a year before the conference, a public call for applications was issued to authors from central banks and universities throughout the world. The scientific committee of the conference made up of the members of the Bank of Russia's Advisory Council on Economic Research played an active part in compiling the final program. A discussant for each paper was selected from researchers studying a similar subject. The guiding principle of the organization was thus an open and competitive selection of applications by scientists and practitioners recognized in the international economic community. The presentation of the papers was supposed to include critique from the discussants and other participants. All in all, over forty papers were submitted to the conference. Only five were selected for the final program. In addition, nine more papers were selected to be presented as part of a specially arranged poster session.

${ }^{4}$ Their policy role for central banks from the viewpoint of the authors of this review.
} 
to them. Today, central banks generally understand the nature of inflation and its mechanisms much better than 20-30 years ago. Central banks' main intellectual efforts should, ideally, focus on other subjects (e.g., financial stability, banking regulation reform and that of the international financial system). As practice suggests, however, there are still quite a few blank spots in understanding inflation.

First, efforts which developed countries' central banks are taking to accelerate price rises in their economies show that it is not only high inflation that can constitute a problem and be an object of studies but also low inflation, which is, moreover, insensitive to a business cycle pattern (missing inflation). Second, the global economy is not static, it keeps changing, taking along national economies, which undergo structural shifts. These are brought about by demographic factors, globalization (expansion in global trade and countries' increased involvement in the creation of added value chains), "the new economy" growth, and robotization. This structural change requires its inflationary implications, and the role of specific factors (internal/global, long-term/short-term, monetary/non-monetary) in inflation dynamics to be studied. The large number of interesting applications submitted to the conference confirmed that the choice of the subject made perfect sense - the subject of inflation is still relevant to researchers from the academic community and central banks.

The most widely represented in the applications submitted to the conference were three areas of research. In the Bank of Russia's view and judging by the programs of similar research conferences on inflation held by central banks recently, ${ }^{5}$ these lines of research are indeed in the focus of central banks' attention now.

The final program was comprised of three major subjects:

\section{1) Inflation expectations and their impact on current inflation}

Inflation expectations are closely monitored by central banks targeting inflation. Inflation expectations are a key factor of actual inflation. Households, firms, and banks' current decisions regarding expenses are based on expectations. Thereby, inflation expectations have an effect on aggregate demand, which is essential to changes in wages and other expenses by companies in an economy (this is eventually reflected in measured inflation). Inflation expectations play an especially important role in decision-making with regard to long-term expenses (buying a house, building a factory) which have an enduring impact on aggregate demand. Change in inflation expectations should therefore also change both current and medium-term economic performance along with medium-term

\footnotetext{
${ }^{5}$ We shall only mention conferences held in 2018: ECB Forum on Central Banking 2018: Price and Wage-Setting in Advanced Economies (Sintra, Portugal, June 18-20, 2018); Inflation: Drivers and Dynamics Conference (The Federal Reserve Bank of Cleveland, USA, May 17-18, 2018); XX Annual Inflation Targeting Conference of the Banco Central do Brasil (Brazil, May 23-25, 2018); The tenth edition of the National Bank of Belgium's biennial conference "Understanding Inflation Dynamics: The Role of Costs, Mark-Ups and Expectations” (Belgium, Brussels, October 25-26, 2018).
} 
inflation dynamics. From this perspective, it becomes vital for central banks to control inflation expectations. In emerging economies, where inflation remains high, central banks aim to control inflation via anchoring inflation expectations and bringing them in line with inflation targets. For advanced economies facing constraints on the employment of conventional monetary policy instruments, with inflation persistently falling short of the central bank's targets, control of inflation expectations becomes another key policy instrument.

As control requires its object, a need to measure inflation expectations arises. To address this task, central banks derive the measures of inflation expectations from theoretical models, surveys, or financial asset pricing. For a variety of reasons, all of the above measures have their advantages and disadvantages. What is more, central banks should focus on the inflation expectations of economic agents (firms, households, and researchers), whose decisions are crucial to inflation dynamics (pricing). The first paper of this session, Computing Long-Term Market Inflation Expectations for Countries without Inflation Expectations Markets by Petra Gerlach-Kristen, Richhild Moessner, and Rina Rosenblatt-Wisch (presenter) of the Swiss National Bank and the Bank for International Settlements, deals with the subject which is particularly relevant to many emerging economies: how to estimate financial market expectations for countries with no financial instruments for direct measurement of inflation expectations.

In the second paper of this session, The Role of Expectations in Changed Inflation Dynamics, Damjan Pfajfar (presenter) and John M. Roberts from the Fed look at what role inflation expectations play in inflation dynamics and what are the factors changing the impact of inflation expectations on inflation. The authors examine how structural change in expectations affects the shape of the Phillips curve, specifically, the diminished response of inflation to the economy's output gap (flattening of the Phillips Curve).

\section{2) Structural factors of inflation}

From expectations, playing a potentially important role in the medium-term price level change, the focus of the second session shifts to the structural factors of inflation, especially those persistent and long-term rather than one-off in nature. One of them is demographic change examined in the paper Demography and Inflation: a Puzzle in Data from 1870 to 2016 by Mikael Juselius from the Bank for International Settlements and Elöd Takáts (presenter) from the Bank of Finland. Structural change in inflation generally takes centerstage in current inflation research. Various global and national structural shifts have set off the process of change in relative prices of many goods and services. Central banks pay special attention to long-term structural change in inflation, change in demographic characteristics being a part of it. Change in the population age structure impacts consumption and savings preferences, the structure of goods and services 
consumption along with demand for financial services (loans/deposits), affecting labor productivity and the production capacity frontier. All of this can have an effect on inflation. And does, as the authors find.

A key question for central banks witnessing such change to answer is to what extent it reflects change in the absolute level of prices and to what extent it is a function of change in relative prices. The difficulty which monetary policy faces in the case of change in relative prices is that when reflected in perceived inflation it can produce a misleading perception of true inflation pressure. For example, when observing computer price decline (controlled for their quality improvement) reflected in an officially observed price index, the regulator may get the impression that inflation is low or slowing down, prompting the conclusion that monetary incentives for enhancing demand are required. This decision would entail an economy's overheating, compensating the disinflationary effect in some goods. Although inflation may in this case stay within the central bank's target, this overheating involves a number of threats. Imbalances may accumulate and bubbles build up in financial asset markets, while a sudden disappearance of disinflation factors would leave the central bank face to face with an abrupt inflation rise, generated by the central bank itself. These considerations raise a question about how central banks should respond to such enduring relative price change of non-monetary nature, affecting, nevertheless, trend inflation (which is a change in the absolute price level).

\section{3) Monetary policy and inflation}

The third session focuses on new insights for central bank policies given the specific features of inflation dynamics and monetary policy transmission observed. These features stem from the globalization of finances (the enhanced role of capital flows as a source of macro fluctuations), the increased dependence of emerging economies on key central banks' policies (see Rey, 2015; Gourinchas, 2017).

New challenges for regulators emerge as central banks pursue new goals, in particular those of securing financial stability. The latter makes it important to coordinate monetary and financial stability policies. The key questions here are whether the achievement of inflation targets can be secured as part of this process and whether central banks should employ monetary policy instruments to address the goals of financial stability. These issues are dealt with in the paper Financial and Price Stability in Emerging Markets: The Role of the Interest Rate by Lorenzo Menna and Martin Tobal (presenter) from the Central Bank of Mexico.

Not only may the emergence of new goals and the need to coordinate policy goals become the source of change in inflation dynamics in response to various shocks but policy transmission may eventually change depending on what equilibrium an economy is functioning in (that of zero or positive interest rates). 
The opposite effects of central bank policies on the exchange rate and inflation were examined in the paper The Effects of Conventional and Unconventional Monetary Policy on Exchange Rates by Barbara Rossi (presenter) and Atsushi Inoue from ICREA - Universitat Pompeu Fabra, Barcelona GSE, and CREI. The key question they pose is what central banks should do to enhance their policy effectiveness (transmission).

The remainder of this review is structured as follows. Each of its sections corresponds to the subject of a particular session, the review of the papers presented in one of the plenary sessions will, for consistency considerations, be complemented by a description of papers on similar subjects presented in the poster session. ${ }^{6}$ The last section sums up the main conclusions the authors' findings suggest for central bank policy.

\section{Inflation expectations and their role in inflation dynamics}

The first session of the conference, Inflation Expectations and Their Role in Inflation Dynamics, was presided by Alberto Fuertes from the Bank of Spain. Rina Rosenblatt-Wisch from the Swiss National Bank presented the paper, Computing Long-Term Market Inflation Expectations for Countries without Inflation Expectation Markets, coauthored with Petra Gerlach-Kristen and Richhild Moessner (Gerlach-Kristen et al., 2018). Markets and central banks monitor long-term inflation expectations. Financial market participants need to forecast future real returns. Central banks need to verify their own credibility and to make sure that inflation expectations are within their target range. There are two possible sources of data for inflation expectations. One is survey-based. Another source is market-based, where inflation expectations are derived from inflation-linked securities, usually from inflation-adjusted bonds or inflation swaps. However, in many countries of the world such markets are either illiquid or nonexistent making the computation of market-based expectations unreliable or impossible.

In the presented paper, the authors propose a solution to this problem by deriving market inflation expectations in a foreign country with liquid swap markets and then using the purchasing power parity and the uncovered interest parity (PPP-UIP) or the purchasing power parity, the uncovered interest parity, and the covered interest parity (PPP-UIP-CIP) to compute expectations in the home country (a paper based on this presentation is published in the current issue of the Russian Journal of Money and Finance).

Olesya Grishchenko from the Federal Reserve Board led the discussion of the first paper. The discussant noted that both PPP and UIP are likely to contain

\footnotetext{
${ }^{6}$ After the second plenary session of the conference, a poster session was held in the hallway. Several authors presented their papers simultaneously.
} 
a time-varying risk premium and, possibly therefore, never hold exactly. In the estimates, inflation expectations in the US are on the rise, while in reality inflation is low, and expectations are dropping. This controversial finding can be explained by the time-varying risk premium. A question from the audience noted that the presence of nontraded goods leads to a further violation of the PPP hypothesis. The presenter replied that empirical studies have shown that PPP and UIP are more likely to hold in the long run than in the short run.

Following on the topic of inflation expectations, Damjan Pfajfar from the Federal Reserve Board presented a paper, coauthored with John Roberts, The Role of Expectations in Changed Inflation Dynamics (Pfajfar and Roberts, 2018). The authors are motivated by the fact that the Phillips curve in the US has become much flatter recently than in previous decades. They present impulse responses from a VAR of an inflation gap and an output gap to a shock to the output gap estimated over two subsamples: 1978-1996 and 1997-2015. Inflation responds much stronger in the early period while the response of output is virtually identical. The authors consider two possible explanations. One explanation is that inflation responds less to aggregate demand shocks conditional on expectations. Another possible explanation is that expectations respond less to fundamentals.

The question of a flatter Phillips curve in the US has been a subject of considerable research. The shape of the Phillips curve is important for forecasting inflation, both for the private sector and for central banks. Understanding the exact source of the change is important for verifying sticky price and sticky information models of price setting. Ball et al. (1988), among others, predict that when inflation is lower, firms adjust prices less often in the context of a sticky price model. Nakamura et al. (2016) provide some evidence using micro data on prices. However, if expectations respond less to fundamentals, this explanation is related to the rational inattention idea of Sims (2003). Economic agents have a limited attention bandwidth. When inflation is low and stable, they choose to pay less attention to it.

To distinguish between the two hypotheses, the authors estimate structural models of inflation and inflation expectations. They allow expectations to deviate from perfect rationality and use surveys as indicators of expectations. The authors propose the following empirical model for the formation of expectations:

$$
\begin{gathered}
E_{t} \Delta p_{t+1}=\mu M_{t} \Delta p_{t+1}+\lambda E_{t-1} \Delta p_{t}+v_{t} \\
S_{t} \Delta p_{t+1}=E_{t} \Delta p_{t+1}+u_{t} \\
u_{t}=p_{u} u_{t-1}+\omega_{t}
\end{gathered}
$$

Here, $\Delta p_{t}$ is inflation. The term $E_{t} \Delta p_{t+1}$ denotes expectations of agents setting prices; $M_{t} \Delta p_{t+1}$ denotes model-consistent expectations; $S_{t} \Delta p_{t+1}$ is the survey 
measure of expectations. Most models assume that agents have model-consistent expectations, but the authors make the following assumption:

$$
E_{t} \Delta p_{t+1}=M_{t} \Delta p_{t+1}
$$

The coefficient $0 \leq \mu \leq 1$ shows that agents receive only a noisy signal of expectations as in Sims (2003). The coefficient $\lambda$ shows that agents' expectations adjust gradually toward a well-informed value as in Carroll (2003). If they are fully rational, then $\lambda=1 . v_{t}$ is a fundamental error; $u_{t}$ is a measurement error in survey measures of expectations that can be serially correlated. The authors complete the model with the hybrid New Keynesian Phillips curve with partial indexation to lagged inflation and a reduced-form model of the output gap $y_{t}$ :

$$
\begin{gathered}
\Delta p_{t}-\gamma \Delta p_{t-1}=\beta\left(E_{t} \Delta p_{t+1}-\gamma \Delta p_{t}\right)+\kappa y_{t}+\epsilon_{t} \\
y_{t}=\phi_{1} y_{t-1}+\phi_{2} y_{t-2}+\phi_{3} \Delta p_{t-1}+\phi_{4} \Delta p_{t-2}+\eta_{t}
\end{gathered}
$$

The authors first estimate the system for the two subsamples, 1978-1996 and 1997-2015, assuming that agents have model-consistent expectations (MCE), that is, $E_{t} \Delta p_{t+1}=M_{t} \Delta p_{t+1}$. They find that the coefficient $\kappa$ falls by a factor of eight from the first to the second subsample signifying a much flatter Phillips curve. The coefficient $\gamma$ is also smaller in the latter sample magnifying the impact of the smaller $\kappa$.

The authors use the University of Michigan survey of consumers' inflation expectations as a measure of subjective inflation expectations. When they add this variable as an observable to the estimation, the slope of the Phillips curve $\kappa$ is considerably larger than in the MCE case. The decline in $\kappa$ from the first to the second subsample is also considerably smaller. Sunspot fluctuations are much less important than in the MCE case as manifested by the smaller estimated variance of the fundamental error $\sigma_{v}$. There is also less propagation as $\lambda$ is smaller. The authors re-estimate impulse responses over the two subsamples with and without the Michigan survey. They show that the change in expectations explains more than half of the reduction in the effect of the aggregate demand shock on inflation.

The authors also experiment with the Survey of Professional Forecasters (SPF) as opposed to the Michigan survey of consumers as a measure of inflation expectations. The estimates of the Phillips curve are broadly similar to the Michigan survey results. However, the estimates for the expectations process are different. The change in expectations explains little of the observed change in the slope of the Phillips curve using the SPF data. The authors conjecture that it is reasonable that professional forecasters still follow the inflation process closely. The measurement error $u_{t}$ is also considerably smaller meaning that professional forecasters follow the inflation process much more closely than households. The authors claim that the Michigan survey results are preferable because firms that 
set prices have expectations closer to those of households rather than professional economists.

Sergey Slobodyan of the Higher School of Economics in St. Petersburg and CERGE-EI in Prague was a discussant. He noted that the design of the Michigan survey is peculiar and may introduce intrinsic persistence. He also noted that because the authors estimate impulse responses using output and inflation gaps, estimates might be sensitive to the choice of the detrending method.

In the poster session, Alberto Fuertes presented a joint paper with Ricardo Gimeno and Jose Manuel Marqués (Bank of Spain), Extraction of Inflation Expectations from Financial Instruments (Fuertes et al., 2018). They present yet another way of obtaining agents' inflation expectations from the data on Latin American markets, where only a few countries have inflation-linked bonds, and no country has inflation options at all. Inflation expectations are important for forecasting inflation both for the private sector and for central banks.

The authors propose an affine model that takes as factors the observed inflation and the parameters generated in the zero-coupon yield curve estimation of nominal bonds. By implementing this approach, they obtain a measure of inflation expectations free of any risk premia since the model breaks down nominal interest rates into the sum of real risk-free interest rates, expected inflation, and the risk premium. The authors obtain inflation expectations for all the horizons computed in the zero-coupon yield curve as well as forward rates such as the expected inflation over the five-year period that begins five years from today (the 5y/5y forward rate). They find that the $5 \mathrm{y} / 5 \mathrm{y}$ inflation expectations seem to be anchored in Chile and Mexico although at a level above a central bank target rate of $3 \%$. On the other hand, long-term inflation expectations in Brazil and Colombia are more volatile and have been fluctuating over time, experiencing a large decrease during 2017.

Antti Ripatti from the University of Helsinki presented a paper, NewsRich Inflation, co-authored with Martin Ellison, Markku Lanne, and Pentti Saikkonen (Ellison et al., 2016). The authors intend to test whether simple models of the US inflation, such as a univariate autoregression (AR) or a bivariate vector autoregression (VAR), are causal. A causal system is one whose present response does not depend on the future values of the input. A non-causal system is one whose response depends on the future values of input. A news-rich process for inflation is a truncated non-causal system in which the largest share of the variance of inflation is attributable not to the current shock but rather to the news about the future. Understanding whether models of inflation are casual is very important for inflation forecasting.

The authors first estimate a univariate AR model of the US inflation, and find that it is purely non-causal. The result suggests that the model is misspecified, and the information set of the econometrician does not span the information set of firms that actually make decisions on prices. The authors then estimate 
a three variable VAR with inflation, output gap, and the nominal interest rate. They still find significant evidence of non-causality. In other words, time prefers to run backwards in the models as the future values of variables determine their present values. The authors are unable to find what data is missing from the information set of the econometrician. They conclude that firms know much more than is typically assumed. The firms are news-rich.

In another paper presented as part of the poster session, Financial Literacy and Inflation Expectations: What Household Survey Data Suggests, Fabio Rumler and Maria Teresa Valderrama from the National Bank of Austria aim to construct "the inflation literacy indicator" based on an extensive household survey. The distinguishing feature of the study is processing individual respondents' answers (whereas surveys usually report only the final estimates of inflation expectations). The authors define inflation literacy as understanding the definition of inflation, the methods of its measurement, sources of information, its causes and relationship with monetary policy. Econometric estimation confirmed the hypothesis that households with relatively higher levels of inflation literacy tend to have lower inflation expectations (greater anchoring to the target). Ex-post, their expectations are found to be more accurate and such respondents less certain about their inflation expectations, reflecting the complexity of factors determining actual future inflation. An important practical conclusion from this study is that central banks really benefit from programs for heightening inflation literacy through better anchoring of expectations to central bank targets.

\section{Structural factors of inflation}

The second session of the conference, Structural Factors of Inflation, was chaired by Oleg Zamulin, Dean of the Economic Faculty of the National Research University Higher School of Economics. Elöd Takáts from the Bank for International Settlements presented a paper, joint with Mikael Juselius, The Enduring Link between Demography and Inflation (Juselius and Takáts, 2018). The paper is motivated by attempts to explain the stubbornly low inflation recently. Recent research has called the business cycle as the sole driver of inflation in question. Bullard, et al. (2012), as well as Summers (2014a, b), suggest demographics and the lifecycle decisions as possible lower frequency drivers of inflation. The purpose of the presented paper is to produce robust empirical evidence on the inflation-demography link, especially between inflation and the age structure of population, using data for 22 developed countries over a long period of 1870-2016.

The link between inflation and demography is a puzzle to the mainstream macroeconomic theory. It matters for monetary policy decisions by central banks because it implies that inflation formation is less understood than usually 
thought. The inflation-demography nexus matters for inflation persistence as well. The age-structure effect implies much lower endogenous persistence of inflation than commonly assumed. It questions traditional explanations of trend inflation - inflation may be not homogeneous as it is thought to be in the long-run and may be driven by relative price changes. It questions the ability of central banks to control trend inflation and to set optimal inflation targets. The inflation-demography link is also important for forecasting lower-frequency inflation. It implies that inflationary pressures are low today for structural reasons but will rise substantially as populations age.

The authors intend to test a hypothesis that the natural rate of interest, that is, the rate at which GDP is growing at its trend rate and inflation is stable, changes with lifecycle savings-investment decisions. Aggregate lifecycle decisions are affected by the age structure of population. However, as the story goes, central banks do not fully internalize these changes in the natural rate. Therefore, trend inflation changes with the age structure.

To test the inflation-demography nexus, the authors assemble an unbalanced panel on 22 advanced economies, such as Australia, Denmark, Japan, the United States, etc., over the 1870-2016 period. Unlike previous studies, the data captures more demographic cycles than the post-war baby boom. Since the focus of the study is on age structure, a naïve estimate would be a regression of inflation on a population share in each age-specific cohort and other regressors. Denoting inflation in country $k$ at time $t$ as $\pi_{k t}$, the share in cohort $j$ as $n_{j k t}$, and a vector of other regressors as $x_{k t}$, the naïve estimate would be:

$$
\pi_{k t}=\alpha_{0}+\sum_{j=1}^{J} \alpha_{j} n_{j k t}+\beta^{\prime} x_{k t}+\varepsilon_{t}
$$

This is problematic because estimates tend to be inefficient when regressors are correlated and the number of estimated parameters is large.

To resolve these econometric issues, the authors use a population polynomial following Fair and Dominguez (1991). For an integer number $P$, a population polynomial has a form:

$$
\tilde{n}_{p k t}=\sum_{j=1}^{J}\left(j^{p} n_{j k t}-j^{p} / J\right)
$$

The authors set $P=4$. Denoting real interest rate as $r$, output gap as $y$, time (year) fixed effects as $\mu_{t}$, and country fixed effects as $\mu_{k}$, the baseline regression becomes:

$$
\pi_{k t}=\mu+\sum_{p=1}^{P} \gamma_{p} \tilde{n}_{p k t}+\beta_{1} r_{k t}+\beta_{2} y_{k t}+\mu_{k}+\mu_{t}+\varepsilon_{k t}
$$

The main finding of the paper is that age structure co-moves with low frequency inflation. The prevalence of dependents - the young and the old - in 
the population is inflationary, while the prevalence of the working age cohorts is disinflationary. However, increased longevity reduces inflation somewhat. This finding is large economically. It explains around one-third of yearly variation in the post-war sample. For example, around 6.5 percentage point disinflation in the US from the 1970s to today is attributable to demographic changes as the share of the young declined. The authors perform a variety of robustness checks and show that the effect is not spurious.

Omar Rachedi from the Bank of Spain was a discussant. The discussant noted that there were many changes over the period in question besides demographic shifts, which may contaminate results. In order to separate the effect of demographics on inflation, he proposed to look for an instrumental variable that would have a direct effect on the right-hand side variable (demographics) but no direct effect on the left-hand side (inflation). He also asked the authors to provide more economic intuition behind their empirical findings. A question from the audience also noted that the population polynomial is very flexible and might lead to the overfitting of data. A comment suggested a link between demography and a credit cycle, which may drive inflation.

During the poster session, Darya Antonova from the European University in St. Petersburg presented a similar paper, Inflation and Demography: the Case of Emerging Economies, co-authored with Yulia Vymyatnina (Antonova and Vymyatnina, 2018). As was previously observed, for example, by Juselius and Takáts (2018), demography might be a factor influencing inflation. This relation can be explained by the various age groups' consumption patterns, earnings, saving behavior, cultural traditions, social structure, etc. The relation might be different in different time periods and at different levels of development. To make demography useful for monetary policy decisions, empirical regularities have to be established and explained using suitable economic theory. Latest studies have identified inflationary pressures in advanced countries stemming from the older generations, as retired people tend to dis-save and stop contributing goods and services to the economy, and the very young, as they also do not contribute to the economy in terms of production.

The authors use annual data for inflation, population, as well as nominal and real interest rates, for 21 emerging economies, such as Argentina, China, Kazakhstan, Russia, South Africa, etc. They find the following results that hold either for the whole sample or for various groups of countries. There are weak signs that demography matters, as regressors are jointly significant. Very young and old seem to be deflationary perhaps due to low savings rate, a culture of joint childcare, and different demographic characteristics. Working age population seems to be inflationary. These results appear to be at odds with the results by Juselius and Takáts (2018), which may be explained by the different sample sizes and time-spans as well as differences in estimation approaches. A positive relation appears between the inflation rate and the policy interest rate, contrary 
to developed countries with the most likely causality from high inflation to high interest rates in a situation of chronic inflation.

The general comment, given contradictory results, is that more research is needed to better understand the role of demographics in the inflation dynamics.

Three more papers were presented as part of the poster session, examining the role of structured characteristics of inflation and change in its dynamics in recent years.

Omar Rachedi from the Bank of Spain presented his paper co-authored with Alessandro Galesi, Services Deepening and the Transmission of Monetary Policy (Galesi and Rachedi, 2016). The authors find empirically and using a theoretical model that the structural transformation of advanced economies, implying the rising share of services in value added and the dwindling share of manufacturing, causes inflation deceleration and, in particular, weakens the response of inflation to monetary shocks. In fact, the share of the US services sector in the services sector's entire intermediate consumption stood at $62 \%$ in 1974 , with industry accounting for just $20 \%$. In 2010, these shares rose to $83 \%$ and $35 \%$ respectively.

The services sector has more rigid pricing mechanisms. First, the share of labor costs is larger in the services sector. Of all cost components, wages are the most rigid to changes. The services sector is almost identical to the non-tradables one, the virtual lack of international competition increases price stickiness: the sector's companies have more room for sticking to their prices, responding to shocks by changing their markup (profit margin). The renewal of assortment is also much less frequent, thus also making prices stickier. As a result, an increase in the services sector's share in value added and consumption makes inflation less responsive to shocks, including to central bank policy. These results partly explain the lesser sensitivity of inflation to the levels of output gap, suggesting that central banks need to take more active steps to counteract recessions.

Also in the poster session, Veronika Tengely from the Central Bank of Hungary presented a paper coauthored with Erzsébet Éva Nagy, External and Domestic Drivers of Inflation: the Case Study of Hungary (Nagy and Tengely, 2018). The authors pay attention to global inflation deceleration occurring since 2013, aiming to study the role of global factors in inflation in Hungary's economy, which has become one of Europe's most open economies after the country's EU accession. The authors employ a number of statistical and econometric methods (principal component analysis, SVAR, GMM estimation of the Phillips curve). The main result produced by the estimation is that the global inflation factor was the predominant driver (explained variance reaching 80\%) of inflation in Hungary since 2012. This factor, which the authors identified by principal component analysis, had not played so significant a role in Hungary's consumer price movements before the EU accession (the paper is also published in the current issue of the Russian Journal of Money and Finance). 
Both of the above papers presented in the poster session suggest that there are two different inflation trends. In developed countries, experiencing the most active structural shift towards the services sector, the role of internal factors should rise, whereas emerging economies, extensively joining global production chains, should, by contrast, see the role of global factors expand. This circumstance makes it even more difficult for emerging economies' central banks to pursue independent monetary policies if they set the goal of strict inflation targeting.

Another paper - Estimates of Exchange Rate Pass-through with Micro Datapresented as part of the poster session by Ufuk Demiroglu (co-authored with Yusuf Emre Akgündüz, Emine Meltem Bastan, and Semih Tümen) from the Central Bank of Turkey (Akgündüz et al., 2018) estimates the exchange rate passthrough effect based on microdata and analyses the factors of pass-through effect heterogeneity across the economy's sectors (in particular, a relationship between the force of the transfer effect and that of competition in a sector). Similar issues are examined in Amiti et al. (2016) as part of a broader empirical approach.

Estimating the pass-through exchange rate changes into prices of traded products is central to understanding the role of the exchange rate in the macroeconomy. It is an important driver of inflation, especially in open economies with a high volume of trade relative to GDP. A good estimate of pass-through is important for a central bank to assess how much of an ongoing rate of inflation is due to exchange rate movements and how much is due to other factors.

Micro data enables the authors to estimate pass-through rates much more reliably and with higher precision than aggregate time-series data. They employ detailed prices for bilateral trade at the 6-digit product level using monthly prices of exports and imports of more than 4,000 products to or from Turkey's more than 130 trade-partner countries. They run separate regressions of import and export prices on the nominal effective Turkish exchange rate, control variables, such as GDP and world commodity prices, as well as country fixed effects, sector fixed effects, year fixed effects, and month fixed effects. Pass-through is about $88 \%$ in imports and $82 \%$ in exports. The estimates for import prices range from $60 \%$ for agricultural goods to nearly $100 \%$ for processed goods. The pattern is similar for exports. The authors explore whether these differences in pass-through can be explained by market characteristics and competition. They find that a higher level of competition on the import side as measured by the number of countries that compete in the Turkish market in a given sector is associated with lower passthrough rates to import prices, but a similar relationship does not exist in export price pass-through. They also find that the level of integration of sectors with the world economy as measured by volumes of exports is associated with lower rates of pass-through to both export and import prices in those sectors. 


\section{Monetary policy and inflation}

Milan Nedeljkovic from the National Bank of Serbia chaired the third session of the conference, Monetary Policy and Inflation. Martin Tobal from the Central Bank of Mexico presented his paper, joint with Lorenzo Menna, Financial and Price Stability in Emerging Markets: The Role of the Interest Rate (Menna and Tobal, 2018). The paper is motivated by the experiences of emerging markets after the global financial crisis of the late 2000s. The crisis showed the dangers of the systemic risk accumulation. Macroprudential policy was suggested as a possible response. A difficulty with macroprudential policy is that it can foster the growth of shadow banking whereby financial market participants try to avoid macroprudential regulation by moving financial activities from the regulated to the unregulated sectors. Another possibility is the use of the monetary policy tools not only for price stability but also for financial stability. The proponents of the "lean against the wind" policy - a policy of raising the interest rate to curb excessive credit growth - argue that higher interest rates are universal and cannot be avoided by moving activities across sectors. Ajello et al. (2016), as well as Cúrdia and Woodford (2016), are examples of models that consider the optimality of the "lean against the wind" policy in a closed economy, such as the US.

However, it is unclear whether the "lean against the wind" policy applies in emerging markets. The emerging markets are less prone to the excessive buildup of domestic credit. Instead, they rely much more on foreign credit. Domestic credit and money aggregates in these countries are smaller relative to foreign capital flows. Thus, financial risks in emerging market economies are explained mostly by capital flows. Recent research, such as Rey (2013), argues that the current macroeconomic situation is characterized by a global financial cycle. Global factors, such as the monetary policy stance in the US and the euro area or the global appetite for risk, affect global capital flows, which in turn affect financial variables in emerging markets. In such a situation, if an emerging economy raises interest rates in an attempt to curb excessive domestic credit growth, it may instead attract foreign capital inflows. The contribution of this paper is to consider whether the "lean against the wind" policy applies in emerging markets given that they are subject to the global financial cycle.

To answer this question, the authors build a model consisting of three major blocks. In the New Keynesian block, demand shocks generate inflation but cannot generate a credit cycle. In the credit and systemic risk block, the authors incorporate savers and borrowers as in Cúrdia and Woodford (2016). Now demand shocks can generate credit accumulation. The authors also follow Ajello et al. (2016) in considering a logistic function modeling the rise in crisis probability with an increase in credit. The third block is an open economy extension where the authors extend the model of Cúrdia and Woodford (2016) to allow domestic agents access to international trade and global financial markets. 
One of the paper's main contributions is extending the model of Cúrdia and Woodford (2016) to the open-economy setup. As in Cúrdia and Woodford (2016), there are borrowers and savers among domestic agents. When savers are given access to global markets, there is a link between capital flows and domestic credit.

The authors consider a two-period scenario, where credit accumulation in period 1 affects crisis probability in period 2 . Denoting credit accumulation as $\tilde{b}_{1}$, average crisis probability as $p$, and the elasticity of crisis probability to credit as $\kappa$, the probability of crisis is described by a logistic function:

$$
P\left(\tilde{b}_{1}\right)=\frac{e^{p+\kappa \tilde{b}_{1}}}{1+e^{p+\kappa \tilde{b}_{1}}}
$$

When the three blocks are put together, the New Keynesian block is described by the Phillips curve and the IS curve. The credit block is described by a credit accumulation equation, and the open economy is represented by an uncovered interest parity. The central bank optimally sets the interest rate in period 1 to minimize a quadratic loss function with a trade-off between optimality in period 1, which requires minimizing the deviations of inflation and output from target, and optimality in period 2, which requires reducing the probability that a financial crisis occurs.

The authors calibrate the model for Mexico. Results suggest that openness in the capital account, and in particular a strong dependence of domestic financial conditions on capital flows, diminishes the effectiveness of monetary policy to "lean against the wind." In an open economy with endogenous financial crises, the optimal policy rate is below the level that would prevail in the absence of endogenous financial crisis and systemic risk. The non-optimality of the "lean against the wind" policy for an emerging economy is covered in the vast "dilemma, not trilemma" literature. See, for instance, the investigation of conditions for this policy optimality in Gourinchas et al. (2017).

Dmitry Matveev from the Bank of Canada was a discussant. The discussant noted that if non-rational expectations are assumed, not only two-period but also long-run expectations matter as shown by Preston (2005). He also pointed out that it would be better to derive a central bank's objective from the principles of consumer welfare optimization instead of assuming a quadratic loss function.

In the last presentation of the main session of the conference, Barbara Rossi from ICREA-Universitat Pompeu Fabra, Barcelona GSE, and CREI presented a joint paper with Atsushi Inoue, The Effects of Conventional and Unconventional Monetary Policy on Exchange Rates (Inoue and Rossi, 2018). A vast body of empirical literature, such as Clarida and Gali (1994) or Eichenbaum and Evans (1995), has established that a monetary policy tightening in a country leads to an appreciation of that country's nominal exchange rate. However, monetary policy has changed over time, especially considering unconventional policies after the global financial crisis of the late 2000s. Under conventional policy, the primary monetary policy instrument in developed countries is the short-term interest rate. Under unconventional policies, a central 
bank cannot lower the short-term rate because of the zero lower bound. Instead, it can alter the size and composition of its balance sheet by purchasing debt obligations to counteract the tightening of financial conditions or to decrease uncertainty. It can also employ forward guidance by issuing announcements regarding the future trajectory of the policy interest rate. The purpose of the presented paper is to quantify and compare the effects of monetary policy on exchange rates in conventional and unconventional times.

When a central bank cannot change the short-term rate, it attempts to affect the entire yield curve by unconventional policies such as asset purchases or forward guidance. This paper uses a novel identification scheme called a "functional VAR." The entire shift in the yield curve is considered a monetary policy shock. The yield curve contains important information on the expected length of the zero lower bound period as well as changes in interest rates expected by financial markets as a result of policies. Importantly for the purposes of the paper, this scheme allows the authors to analyze conventional and unconventional policies in a unified way. They show that this model is equivalent to a vector autoregression. Identification can be achieved using any of the existing methods for VARs, such as Cholesky decomposition, sign restrictions, or high-frequency data.

The authors concentrate on the US monetary policies and the US dollar (USD) exchange rates. They identify monetary policy shocks as shifts in the whole term structure of government bond yields in a narrow window of time around monetary policy announcements. In the period of conventional policies, the authors find that an increase in the US interest rates generally leads to an appreciation of the USD. This result is consistent with previous empirical literature. However, there is heterogeneity in responses as the effect on exchange rates depends on how the shock changes agents' expectations. The authors also find that, overall, unconventional monetary policy has similar effects to conventional expansionary monetary policy, leading to an increase in both output growth and inflation; the response is hump-shaped, peaking around one year to one year and a half after the shock. However, again, the response depends on the shape of the shock, that is, on how it affects the yield curve and expectations. Each shock is potentially different and may result in different exchange rate responses.

Tsvetelina Nenova from London Business School led the discussion. She pointed out that it would be interesting to compare the results of the paper with the now vast literature on high-frequency identification in VARs, such as MirandaAgrippino and Ricco (2018). A question from the audience suggested using the data on Treasury Inflation Protected Securities (TIPS) to identify unconventional monetary policy shocks and to compare the results to shocks from this paper.

Two papers reviewed in the poster session looked at the effects of monetary policy on inflation. ${ }^{7}$ Anna Pestova from the CERGE-EI presented the paper written

\footnotetext{
${ }^{7}$ Another paper, presented by Omar Rachedi in the poster session, Services Deepening and the Transmission of Monetary Policy, also deals with this subject but focuses on structural changes of the inflation structure and is therefore described in Section 2 of this review.
} 
jointly with Natalia Rostova, Measuring Monetary Policy (In)effectiveness in Russia: a Structural Dynamic Factor Model Approach. The authors examine the effects of monetary policy shocks identified by them on the macro performance of the Russian economy in 2010 - 2017 using the structural dynamic factor model (SDFM). Based on the results obtained, the authors conclude that monetary policy tightening (contractionary monetary shocks) in Russia has a limited ability to restrain inflation and maintain exchange rate stability. As their conclusions suggest, shocks which can potentially affect inflation in Russia are exogenous exchange rate shocks.

The paper provoked a lively discussion during the poster session. The main comments are as follows:

- The identification of monetary policy shocks is a robustness test. To what extent did the identified monetary policy shocks agree with market perception of these policy changes as shocks? In other words, the results obtained need to be tested as part of the narrative approach to the identification of shocks.

- Shock identification is not unambiguous, identified shocks fit quite well - via a rise in the key interest rate and monetary aggregate contraction - into the oil shock, which triggers a drop in money demand (a rise in dollarization), an increase in inflation expectations to which a central bank, following the rule, responds by policy tightening.

- Why should macro variables respond to monetary policy shocks rather than to policy itself under the rule (implemented under a certain Taylor rule)? If a central bank and its policy rule are credible to market participants they understand that any deviations from this rule (shocks) should be temporary, producing no significant effects in the medium term. The authors, however, obtain such permanent effects for real variables (the performance of industrial output, investment and import). Then this implies, first, that monetary policy is not neutral and, second, that by "shocking" economic agents a central bank would impact real economy (economic agents' decisions regarding production and consumption) more effectively than if it strictly follows the rule well communicated by itself. These results require theoretical substantiation - a description of the theoretical mechanism producing such results.

- As regards the Russian economy, given the great role of commodity price movements in the ruble exchange rate fluctuations (even if an allowance is made for the effect of the budget rule), the concept of "the exogenous exchange rate shock" raises some questions. Should it be understood as traders' mistakes in the currency market, and how often do such mistakes occur? Maritta Paloviita from the Bank of Finland presented the results of the study What Does "Below, but Close to Two Percent" Mean? Assessing the ECB's Reaction Function with Real Time Data, conducted jointly with Markus Haavio, Pirkka Jalasjoki, and Juha Kilponen. The authors seek to identify the ECB board of directors' reaction function to macroeconomic shocks and to assess the role of past inflation. The reaction function shows what kind of expected or actual changes in 
inflation performance trigger ECB policy response. An unclear communication of the ECB's inflation target may be a factor of inefficient monetary policy transmission - anchoring of inflation expectations. An asymmetric response to inflation rising above or declining below the target may make it harder or easier to reach the target if inflation stays far from the target range for a long time.

The authors find that, first, the ECB board's reaction function is asymmetric: the ECB is more concerned about inflation rising above $2 \%$ than about it falling below $2 \%$. This may make it difficult for inflation to reach $2 \%$ because this causes markets' doubts about the ECB's willingness to tolerate a temporary inflation rise above the target. The ECB response to past inflation surprises (shocks) suggests that its policy target lies close to the $1.6-1.7 \%$ level.

\section{Conclusion}

The Bank of Russia's conference Inflation: New Insights for Central Banks allows the following conclusions to be formulated:

1. The global nature of financial markets with their mutual links and lack of arbitrage can make up for the insufficient development of some national markets as regards deriving information about inflation expectations from various financial instruments. Still, a question has yet to be answered about what information these measures provide concerning the non-tradable part of the national economy and prices, which may be large enough. The second, more important, question is how to identify the group of economic agents which are the most important to inflation dynamics.

2. What the weakening of inflation response to changes in the output gap found in economic studies may suggest is that inflation expectations have less information content and are less related to actual economic performance. This may result from low inflation - when firms no longer pay attention to it. Under these circumstances, the communication policy of inflation expectations anchoring should play an important role.

3. Structural factors, such as demographic and productivity changes, may for a long time affect the trend of the measured consumer price index. For central banks, difficulties arise if such long-standing changes take the form of changes in relative prices, i.e., affect a small group of goods (or even one item of goods). Disinflation or inflation acceleration occurring in this process make central banks weigh alternatives: counteract inflation deviation from the target with an array of monetary instruments or decide against responding to these changes and put up with of these extreme alternatives have their advantages and disadvantages. In practice, the implications of either policy should be weighed thoroughly.

4. Monetary policy in a small open emerging economy with capital flows very sensitive to interest rate changes may prove to be an inefficient instrument for combatting exogenous (or associated with a major foreign central bank's policy) 
capital flows (pressure on the exchange rate and inflation). These capital flows can potentially become a source of imbalances buildup in a national financial system (excessive debt accumulation) and a trigger of a systemic crisis. Macroprudential policy should, in such a situation, become an additional instrument of safeguarding monetary policy autonomy. An important open practical question: the coordination of monetary and macroprudential policy given various policy lags, periods within which targets are to be met, and risk realization periods (typically 1-2 years for inflation, may be as long as decades for financial stability risks).

5. A central bank's communication policy has totally different effects on changes in macro performance and financial time series, depending on whether it is oriented to the closest point in the interest rate curve (the current key rate) or the entire curve. Market participants' expectations of a central bank's future actions play a determining role in the exchange rate and inflation response to current changes in a central bank's policy.

\section{References}

Ajello, A., Laubach, T., López-Salido, D. and Nakata, T. (2016). Financial Stability and Optimal Interest-Rate Policy. Finance and Economics Discussion, Series 2016-067. Washington: Board of Governors of the Federal Reserve System.

Akgündüz, Y.E., Demiroğlu, U., Baştan, E.M. and Tümen, S. (2018). Estimates of Exchange Rate Pass-Through with Micro Data. [manuscript] Central Bank of the Republic of Turkey.

Amiti, M., Itskhoki, O. and Konings, J. (2016). International Shocks and Domestic Prices: How Large are Strategic Complementarities? NBER Working Paper, N 22119.

Antonova, D. and Vymyatnina, Y. (2018). Inflation and Demography: the Case of Emerging Economies. [manuscript] European University in St. Petersburg.

Ball, L., Mankiw, N. G. and Romer, D. (1988). The New Keynesian Economics and the Output-Inflation Trade-Off. Brookings Papers on Economic Activity, 19(1), pp. 1-82.

Bullard, J., Garriga, C. and Walker, C. (2012). Demographics, Redistribution, and Optimal Inflation. Federal Reserve Bank of St. Louis Review, 94 (6), pp. 419-439.

Carroll, C.D. (2003). Macroeconomic Expectations of Households and Professional Forecasters. The Quarterly Journal of Economics, 118(1), pp. 269-298.

Clarida, R. and Gali, J. (1994). Sources of Real Exchange Rate Fluctuations: How Important are Nominal Shocks? Proceedings, Federal Reserve Bank of Dallas.

Cúrdia, V. and Woodford, M. (2016). Credit Frictions and Optimal Monetary Policy. Journal of Monetary Economics, 84(C), pp. 30-65.

Eichenbaum, M. and Evans, C.L. (1995). Some Empirical Evidence on the Effects of Shocks to Monetary Policy on Exchange Rates. Quarterly Journal of Economics, 110(4), pp. 975-1009.

Ellison, M., Lanne, M., Ripatti, A. and Saikkonen, P. (2016). News-Rich Inflation. [manuscript] University of Helsinki.

Fair, R. and Dominguez, K. (1991). Effects of the Changing U.S. Age Distribution on Macroeconomic Equations. American Economic Review, 81, pp. 1276-94. 
Fuertes, A., Gimeno, R. and Marqués, J.M. (2018). Extraction of Inflation Expectations from Financial Instruments. [manuscript] Bank of Spain.

Galesi, A. and Rachedi, O. (2016). Structural Transformation, Services Deepening, and the Transmission of Monetary Policy. Bank of Spain, Working Papers, N 1615.

Gerlach-Kristen, P., Moessner, R. and Rosenblatt-Wisch, R. (2018). Computing LongTerm Market Inflation Expectations for Countries without Inflation Expectation Markets. Russian Journal of Money and Finance, 77(3), pp. 23-48.

Gourinchas, P.O. (2017). Monetary Policy Transmission in Emerging Markets: An Application to Chile. Series on Central Banking, Analysis and Economic Policy, vol. XX. Banco Central de Chile.

Inoue, A. and Rossi, B. (2018). The Effects of Conventional and Unconventional Monetary Policy on Exchange Rates. [manuscript] Vanderbilt University and ICREA-Univ. Pompeu Fabra, Barcelona GSE, and CREI.

Juselius, M. and Takáts, E. (2018). The Enduring Link between Demography and Inflation. BIS Working Papers, N 722.

Menna, L. and Tobal, M. (2018). Financial and Price Stability in Emerging Markets: the Role of the Interest Rate. BIS Working Papers, N 717.

Miranda-Agrippino, S. and Ricco, G. (2018). The Transmission of Monetary Policy Shocks. [manuscript] Bank of England.

Nagy, E.E. and Tengely, V. (2018). External and Domestic Drivers of Inflation: the Case Study of Hungary. Russian Journal of Money and Finance, 77(3), pp. 49-64.

Nakamura, E., Steinsson, J., Sun, P. and Villar, D. (2016). The Elusive Costs of Inflation: Price Dispersion During the US Great Inflation. NBER Working Paper, N 22505.

Paloviita, M., Haavio, M., Jalasjoki, P. and Kilponen, J. (2017). What Does 'Below, but Close to, Two Percent' Mean? Assessing the ECB's Reaction Function with Real Time Data. Bank of Finland Research Discussion Papers, N 29.

Pfajfar, D. and Roberts, J.M. (2018). The Role of Expectations in Changed Inflation Dynamics. [manuscript] Federal Reserve Board.

Preston, B. (2005). Learning about Monetary Policy Rules when Long-Horizon Expectations Matter. International Journal of Central Banking, 1(2), pp. 81-126.

Rey, H. (2015). Dilemma not Trilemma: The Global Financial Cycle and Monetary Policy Independence. NBER Working Paper, N 21162. May 2015, revised February 2018.

Sims, C.A. (2003). Implications of Rational Inattention. Journal of Monetary Economics, 50(3), pp. 665-690.

Summers, L. (2014a). Reactions on the New Secular Stagnation Hypothesis. In: C. Teulings and R. Baldwin, eds. Secular Stagnation: Facts, Causes and Cures. VoxEU ebook, pp. 27-40.

Summers, L. (2014b). US Economic Prospects: Secular Stagnation, Hysteresis, and the Zero Lower Bound. Business Economics, 49(2), pp. 65-73. 